\title{
Geociências
}

\section{Fluoreto nas águas subterrâneas dos aqüíferos Tubarão e Cristalino, região de Salto-Indaiatuba (SP)}

\author{
Fluoride in the groundwater of the Tubarão and Crystaline aquifers, \\ Salto-Indaiatuba region (SP)
}

\section{Raphael Hypolito \\ Químico, Professor Dr. Titular do Instituto de Geociências da Universidade de São Paulo - IGc/USP \\ Departamento de Geologia \\ Sedimentar e Ambiental, Pesquisador do Centro de Pesquisas de Águas Subterrâneas - CEPAS/IGc/USP E-mail: rhypo@igc.usp.br}

\section{Sibele Ezaki}

Geóloga, Msc., Pesquisadora do Instituto Geológico da Secretaria do Meio Ambiente do Estado de São

Paulo - IG/SMA

Pós-graduanda do IGc/USP

E-mail: sibezaki@igeologico.sp.gov.br

\section{Annabel Pérez-Aguilar \\ Geóloga, Dra., Pesquisadora do Instituto Geológico da Secretaria do Meio Ambiente do Estado de São \\ Paulo - IG/SMA \\ E-mail: annabelp@igeologico.sp.gov.br}

\section{Resumo}

Na região de Salto-Indaiatuba, SP, foram detectadas concentrações anômalas de fluoreto ( $\left.>1,5 \mathrm{mg} \mathrm{dm}^{-3}\right)$ em águas de 19 poços tubulares profundos, com valores médios de $3,03 \mathrm{mg} \mathrm{dm}^{-3}$ e máximo de $6,95 \mathrm{mg} \mathrm{dm}^{-3}$, constituindo restrição ao uso das águas para consumo humano. Os poços extraem água dos Aqüíferos Tubarão (sedimentar, granular) e Cristalino (granítico, fissural) e são utilizados para fins sanitários e/ou em processos industriais. Suas águas são predominantemente do tipo bicarbonatadas e bicarbonatadas-sulfatadas, com altas concentrações de $\mathrm{HCO}_{3}^{-} \mathrm{e}$ $\mathrm{Na}^{+}$e valores de $\mathrm{pH}$ entre 7,5 e 10,0. As maiores concentrações de $\mathrm{F}^{-}$ocorrem em poços dos Aqǘf́ros Tubarão e Tubarão/Cristalino. A presença do íon $\mathrm{F}^{-}$em águas subterrâneas é controlada por elevados valores de $\mathrm{pH}$, alcalinidade e disponibilidade de flúor. A fonte de fluoreto nos Aqüíferos Tubarão e Cristalino pode estar associada à percolação de fluidos hidrotermais relacionada aos derrames de lava do Mesozóico associados à abertura do Atlântico Sul e/ou hidrólise de minerais e argilominerais ricos em flúor.

Palavras-chave: Fluoreto, águas subterrâneas, Aqüífero Tubarão, Aqüífero Cristalino.

\begin{abstract}
Anomalous concentrations of fluoride in groundwater were identified in 19 drilling wells in the Salto-Indaiatuba region, São Paulo State, with an average concentration of $3.03 \mathrm{mg} \mathrm{dm}^{-3}$ and a maximum of $6.95 \mathrm{mg} \mathrm{dm}^{-3}$, which constitute a restriction for the water's usage in terms of human consumption. The wells exploit water from the Tubarão Aquifer (sedimentary, granular) and Crystalline Aquifer (granitic, fractured), used for sanitary or industrial purposes. These groundwaters are typically $\mathrm{HCO}_{3}$ and $\mathrm{HCO}_{3}-\mathrm{SO}_{4}$ types, with high concentrations of $\mathrm{HCO}_{3}$-and $\mathrm{Na}^{+}$and high $\mathrm{pH}$-values between 7.5 and 10.0. The highest concentrations of $\mathrm{F}^{-}$ are associated to the Tubarão and Tubarão/Crystalline aquifer drilling wells. The presence of $\mathrm{F}^{-}$in groundwater is controlled by these high $\mathrm{pH}$-values, alkalinity, and fluorine availability. The source of fluoride in the Tubarão and Crystalline Aquifers can be related to the percolation of hydrothermal fluids associated with Mesozoic lava flow, emplaced due to the opening of Atlantic Ocean and/or hydrolysis of fluorine-rich minerals and clay minerals.
\end{abstract}

Keyword: Fluoride, groundwaters, Tubarão Aquifer, Crystalline Aquifer. 


\section{Introdução}

A região de Salto e Indaiatuba constitui atualmente um pólo urbano e industrial em expansão localizado a aproximadamente $110 \mathrm{~km}$ a noroeste da cidade de São Paulo, SP. Há uma crescente demanda de água, mas também sérias limitações quanto ao potencial de abastecimento público pelos mananciais superficiais, na maioria, degradados. Apesar da baixa produtividade dos aqüíferos nessa região, sua exploração tornou-se importante alternativa. Entretanto, constataram-se teores elevados de flúor nas águas subterrâneas captadas por alguns poços tubulares profundos de uso privado, utilizados em sua totalidade para fins sanitários, domésticos ou em processos industriais.

Para a Organização Mundial da Saúde, a concentração máxima de fluoreto em água potável é de $1,5 \mathrm{mg} \mathrm{dm}^{-3}$ (WHO, 2006), valor também adotado pela Portaria $\mathrm{n}^{\circ} 518$, de 25/03/2004 do Ministério da Saúde do Brasil. A ingestão contínua de águas com concentrações elevadas de flúor pode acarretar riscos à saúde, como a fluorose dentária, identificada por leves manchas esbranquiçadas até castanhas no esmalte do dente, e doenças do esqueleto que podem propiciar fratura de ossos (WHO, 2006).

Os teores médios de flúor nas águas do mar e em rios e lagos são, respectivamente, de $1 \mathrm{mg} \cdot \mathrm{dm}^{-3} \mathrm{e}<0,5 \mathrm{mg} \cdot \mathrm{dm}^{-3}$ (WHO, 2006). Nas águas subterrâneas, os teores são variáveis e dependem da natureza das rochas, da ocorrência de minerais com flúor e do grau de interação rocha-água (Chae et al., 2007). No entanto, sua presença também pode estar associada a atividades humanas em indústrias como a de alumínio (criolita), de fertilizantes (fluorapatita, gesso e formulações NPK) (Conceição \& Bonotto, 2005), produção de ácido fosfórico, utilização como fundente nas indústrias metalúrgica e cerâmica e até mesmo no setor nuclear, onde compostos fluorados são utilizados.

Águas com elevadas concentrações de fluoreto ocorrem em diversas regiões no mundo e sua presença, normalmente, está associadas a: 1) rochas graníticas e gnáissicas (Índia, Paquistão, África Oeste, Tailândia, China, Coréia, Sri Lanka, Sul da África; EUA, Reino Unido e Noruega); 2) rochas vulcânicas (Rift do Leste Africano, com até $690 \mathrm{mg} . \mathrm{L}^{-1}$ de flúor, Vale da Jordânia; Sudão, Etiópia, Uganda; Índia, Havaí); 3) sedimentos de origem marinha em áreas montanhosas (Irâ-Síria, Turquia, Iraque até a região mediterrânea, Argélia e Marrocos, sul dos EUA, sul da Europa e sul da USSR) (Hem, 1985; Garici \& Davies, 1993; Ampabire et al., 1997; Banks et al., 1998; Kim \& Jeong, 2005; WHO, 2006; Ozsvath, 2006; Guo et al., 2007; Chae et al., 2007).

Na bacia do Paraná e no seu embasamento cristalino, há diversas regiões que apresentam anomalias de flúor nos aqǘferos associados (Kimmelmann \& Silva, 1990; Fraga, 1992; Licht, 2001; Sracek \& Hirata, 2002; Silvério da Silva et al., 2006; Kern et al., 2008; Nanni, 2008; Viero et al., 2009).

Nas águas subterrâneas, o fluoreto (F-) é a forma mais comum de ocorrência do flúor, podendo formar complexos estáveis com magnésio, boro $\left(\mathrm{BF}(\mathrm{OH})_{3}\right.$, $\left.\mathrm{BF}_{2}(\mathrm{OH})_{2}^{-}, \mathrm{BF}_{3}(\mathrm{OH})^{-}\right)$, compostos orgânicos e, ocasionalmente, com alumínio $\left(\mathrm{AlF}^{2+}, \mathrm{AlF}_{2}^{+}, \mathrm{AlF}_{3}, \mathrm{AlF}_{4}^{-}, \mathrm{AlF}_{5}^{-}, \mathrm{AlF}_{6}^{-}\right)$, ferro $\left(\mathrm{FeF}^{2+}, \mathrm{FeF}_{2}{ }^{+}, \mathrm{FeF}_{3}\right)$ e cálcio, embo$\mathrm{ra} \mathrm{Al}^{3+} \mathrm{e} \mathrm{Fe}^{3+}$ tendam a precipitar como hidróxidos e $\mathrm{Ca}^{2+}$ como carbonatos e sulfatos (Hem, 1968; Kern et al., 2008).

As fontes de flúor são minerais presentes nas rochas da crosta (ígneas, metamórficas ou sedimentares) ou do manto, nos magmas, assim como também fluidos hidrotermais associados a processos magmáticos ou metamórficos (Allmann \& Koritnig, 1969; Edgar \& Arima, 1985; Fraga, 1992). A incorporação de flúor nos minerais a partir de uma fase fluida rica nesse elemento, ou vice-versa, depende de diversas variáveis como temperatura, pressão, $\mathrm{pH}$, Eh, composição dos minerais, composição da fase fluida, razão rocha-água, tempo de reação e composição do magma quando constitui uma das varáveis envolvidas (Edgar \& Arima, 1985; Zhu \& Sverjensky, 1991; Ampabire et al. 1997).
O objetivo desse trabalho é caracterizar as concentrações de fluoreto nas águas subterrâneas das regiões de Salto e Indaiatuba e estabelecer correlações dessas concentrações com os diferentes aqüíferos presentes na região, representados pelo Aqüífero Tubarão, que constitui um aqǘf́ero sedimentar de porosidade granular, e pelo Aqüífero Cristalino, Pré-Cambriano, fissural, hospedado em rochas granitóides.

\section{Contexto geológico}

$\mathrm{Na}$ área estudada afloram rochas sedimentares do Subgrupo Itararé (Grupo Tubarão) presentes na borda leste da bacia do Paraná e rochas do embasamento cristalino constituído por rochas metamórficas e diversos corpos granitóides (Almeida et al., 1981).

Neves (2005) agrupou as rochas metamórficas que afloram ao norte das Zonas de Cisalhamento Jundiuvira e Itu no Complexo Amparo e, também, agrupou aquelas que afloram ao sul dessas zonas de cisalhamento nos Grupos São Roque e Serra do Itaberaba. A todas essas unidades foram atribuídas idades pré-cambrianas, tendo sido o Complexo Amparo posicionado na coluna estratigráfica como sendo mais velho e o Grupo São Roque como mais novo.

As rochas do Complexo Amparo foram subdivididas por essa autora em quatro unidades onde predominam migmatitos, quartzitos, xistos e gnaisses, estando as rochas do Grupo Serra do Itaberaba representadas por uma unidade de rochas metavulcânicas e as do Grupo São Roque, essencialmente, por metarritmitos e metarenitos e, de forma subordinada, por filitos e quartzitos.

As rochas do Complexo Amparo encontram-se cortadas por diversos corpos de granitóides com idades variando entre o Neoproterozóico e Eo-Paleozóico, sendo mais representativos aquelas associadas ao Complexo Granitóide Itu (Pascholati, 1990; Galembeck, 1997). De forma geral predominam microclínio granitos leucocráticos com baixas concentrações de biotita \pm anfibólio (Galembeck et al., 2001). 
As rochas sedimentares do Subgrupo Itararé, de idade permocarbonífera (Souza, 2006), cobrem, principalmente, corpos granitóides e, secundariamente, rochas do Complexo Amparo. Correspondem à unidade basal, a mais espessa do Grupo Tubarão, e foram depositadas, principalmente, em ambientes lacustres, deltaicos e marinhos presentes na interface entre o continente e a plataforma marinha, sob influência glacial, periglacial e interglacial (Rocha-Campos, 1967; Saad, 1977; Stevaux et al., 1987; Zalán et al., 1990; Petri \& Pires, 1992; Santos et al., 1996, Salvetti, 2005). Como conseqüência, observam-se, horizontal e verticalmente, uma grande variação e uma interdigitação de fácies.

Os últimos eventos de deposição de sedimentos estão representados por coberturas de depósitos coluviais e eluviais do Terciário constituídos, principalmente, por conglomerados, argilitos e arenitos (Neves, 2005).

$\mathrm{Na}$ região, há presença de três grandes grupos de lineamentos, que possuem, respectivamente, orientações variando entre $\mathrm{N} 45^{\circ}-65^{\circ} \mathrm{W}, \mathrm{N} 50^{\circ}-70^{\circ} \mathrm{E}$ e E-W. Zonas de fraqueza NW e NE foram herdadas do embasamento Pré-Cambriano e reativadas durante o Fanerozóico e as estruturas E-W se desenvolveram, principalmente, associadas à ruptura do supercontinente Gondwana e à abertura do Atlântico Sul, durante o Mesozóico, em regime de esforços extensivo (Zalán et al., 1990; 1991). As falhas de Cachoeira, da Fonte, Cururu e Piraí, de direção $\mathrm{NW}$, localmente colocam em contato corpos granitóides com rochas do Complexo Amparo (Neves, 2005). Na região estudada, foram medidas falhas normais de direção média N45E (granitóides) e N25W (granitóides e Subgrupo Itararé). Anomalias termais do manto geraram grandes derrames de lavas da Formação Serra Geral da bacia do Paraná e de diques de diabásio orientados, preferencialmente, na direção NW. Esse evento de esforços extensivos provocou uma significativa reativação de zonas de fraqueza NE (Zalán et al., 1991).

\section{Materiais e métodos}

Foram consultados relatórios de poços tabulares profundos da região de Salto e Indaiatuba nos arquivos do Departamento de Águas e Energia Elétrica (DAEE) da Secretaria de Saneamento e Energia do Estado de São Paulo e de empresas particulares atuantes na região. Foram levantados 60 relatórios de poços, na região de Salto, e 61, na porção sul de Indaiatuba, que possuíam dados analíticos de água. Desse total de 121 relatórios, nesse estudo foram considerados 68 relatórios de poços que possuíam dados analíticos de concentração de fluoreto na água, profundidade, $\mathrm{pH}$ e condutividade elétrica, mas que não possuíam dados completos com relação à concentração de íons de interesse.

Para suprir essa deficiência, efetuou-se, a partir do cadastro dos 68 relatórios, a seleção de 31 poços para amostragem de água (poços n. 1 a 31), dos quais 15 explotam o Aqüífero Cristalino, 8, o Aqüífero Tubarão, 6 são poços mistos (Aqüíferos Cristalino/Tubarão) e 2 não possuem informações sobre o aqüífero (Figura 1). Foram, também, cadastrados e amostrados 22 poços cacimba do Município de Salto, que se encontram no manto de intemperismo. As coletas foram realizadas, preferencialmente, na saída do poço para a caixa d'água e, no caso dos poços cacimba, em 12 deles utilizou-se amostrador descartável do tipo bayler.

Em todas as amostras de água foram analisados, em campo, os seguintes parâmetros: Eh, utilizando-se eletrodos de vidro e combinado de platina, modelo multiline $\mathrm{P} 3$ e marca WTW, $\mathrm{pH}$, temperatura e condutividade elétrica, utilizando eletrodos P3/oxidação/condução da marca WTW, e alcalinidade $\left(\mathrm{HCO}_{3}{ }^{-}\right.$e $\left.\mathrm{CO}_{3}{ }^{2-}\right)$, conforme método descrito por Hypolito et al., 2008.

As amostras de água foram acondicionadas em frascos de polietileno $(500 \mathrm{ml})$, preservadas à temperatura inferior a $4^{\circ} \mathrm{C}$ e encaminhadas para os laboratórios do Centro de Pesquisas de Águas Subterrâneas (CEPAS) do Instituto de Geociências da Universidade de São Paulo (IGc/USP), onde foram filtradas a vácuo com membrana de acetato celulose de $0,45 \mu \mathrm{m}$. Em seguida, uma primeira alíquota foi preservada com $\mathrm{HNO}_{3}(\mathrm{pH}<2)$ para posterior determinação da concentração dos cátions $\mathrm{Ca}^{2+}$, $\mathrm{Mg}^{2+}$ por Espectrofometria de Absorção Atômica, utilizando o equipamento GBC 932B Plus, obtendo-se resultados expressos em $\mathrm{mg}$. $\mathrm{dm}^{-3}$. Uma segunda alíquota foi preservada com $\mathrm{H}_{2} \mathrm{SO}_{4}(\mathrm{pH}<2)$ para posterior determinação de $\mathrm{Na}^{+}$e $\mathrm{K}^{+}$por Fotometria de Chama, através da utilização do equipamento B262 da Micronal, obtendo-se resultados expressos em $\mathrm{mg} \mathrm{dm}^{-3}$. Uma terceira alíquota foi mantida refrigerada para posterior determinação dos ânions $\mathrm{SO}_{4}^{2-}, \mathrm{Cl}^{-}$e $\mathrm{F}^{-}$por Cromatografia Líquida, utilizando o equipamento ICS 90 da Dionex, obtendo-se resultados expressos em mg.dm ${ }^{-3}$.

Após a obtenção dos dados analíticos de $\mathrm{Na}, \mathrm{K}, \mathrm{Ca}, \mathrm{Mg}, \mathrm{Cl}, \mathrm{SO}_{4}, \mathrm{HCO}_{3}+\mathrm{CO}_{3}$, nas amostras de águas coletadas, a classificação hidroquímica das mesmas foi obtida através do uso do programa AquaChem 5.1.

Para determinar o teor total de flúor em rochas que afloram na área de estudo, foram analisadas 4 amostras de granito (GR3D; GR5E; GR6 e GR10) e 3 amostras de rochas sedimentares (um folhelho SED4e, um argilito SED2Ae e um siltito SED5b). Essas amostras foram prensadas até cominuição menor do que $0,5 \mathrm{~cm}$ de diâmetro, sendo, posteriormente, quarteadas. Na seqüência, uma alíquota de 80 gramas de cada amostra foi moída em moinho de ágata até aproximadamente $100 \%$ passante em peneira de malha 200mesh. Posteriormente, cada amostra foi pulverizada em fração menor do que 700 mesh e feita uma pastilha para análise no Laboratório de Fluorescência de Raios X do IGc/USP com o equipamento PW2400 da Phillips.

Foram efetuadas análises mineralógicas nas 4 amostras de granito através do estudo de seções delgadas utilizando-se microscópio de luz transmitida. Nas frações argila e silte fino, das 3 amostras de rochas sedimentares, as análises foram 


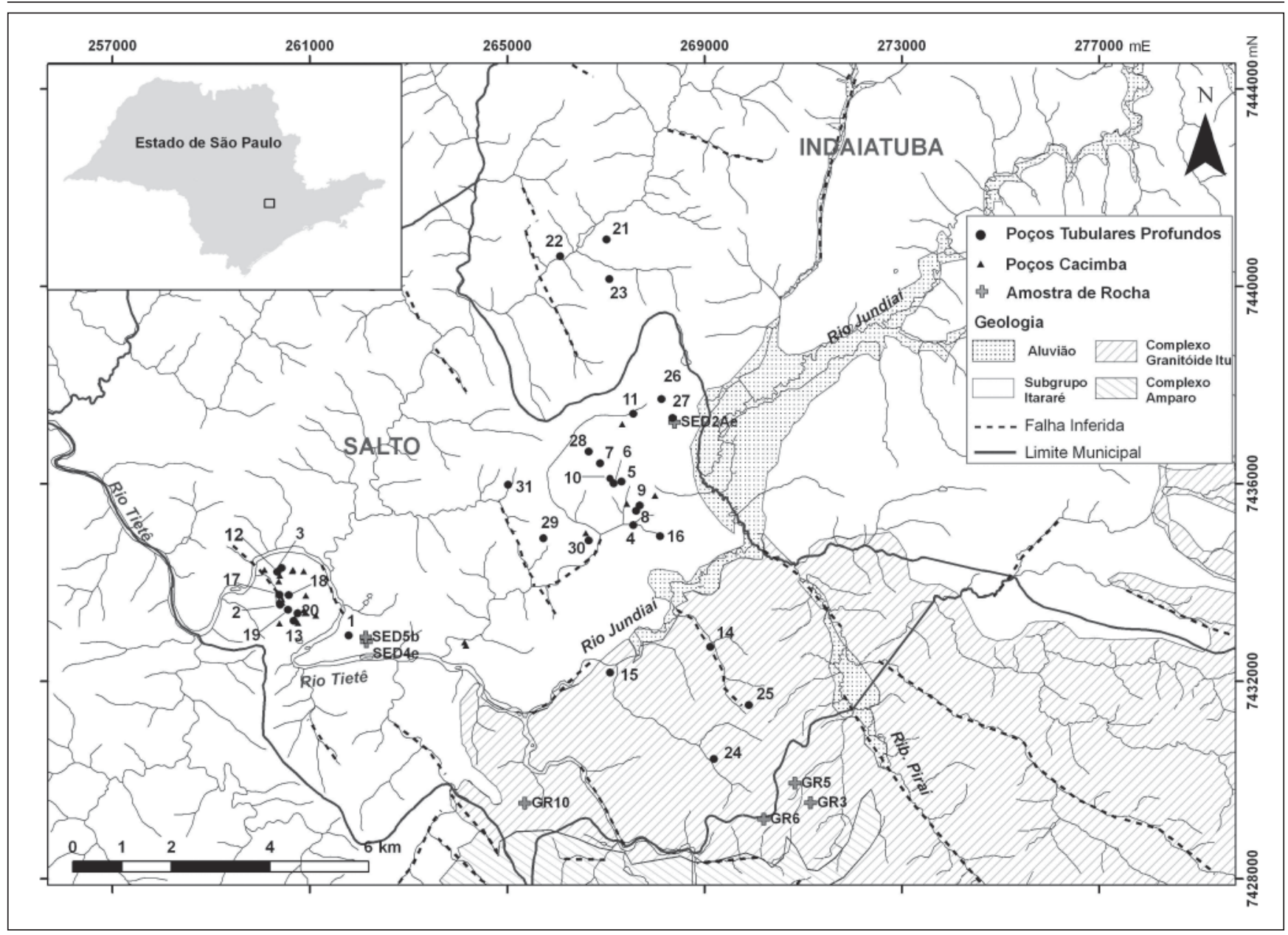

Figura 1 - Localização dos pontos de amostragem de águas subterrâneas e rochas e geologia da área estudada segundo Neves (2005).

efetuadas no Laboratório de Difração de Raios X do IGc/USP, utilizando-se o equipamento X/D5000 da Siemens. A localização dessas amostras pode ser vista na Figura 1.

\section{Resultados}

$\mathrm{Na}$ Tabela 1, são apresentados dados analíticos de elementos maiores das águas de poços tubulares da região de Salto/Indaiatuba. Em todos os poços, foram obtidos dados relativos à $\mathrm{pH}$, condutividade elétrica e concentração de fluoreto da água. Somente nos poços n. 1 a 32, 41, 49 e 60 foram obtidos resultados completos de ânions e cátions na água, os quais foram utilizados para a classificação química das águas dos aqüíferos estudados.
As condutividades elétricas médias das águas do Aqüífero Tubarão, Cristalino,

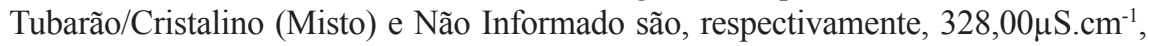
$535,90 \mu \mathrm{S} . \mathrm{cm}^{-1}, 251,86 \mu \mathrm{S} . \mathrm{cm}^{-1}$ e $358,30 \mu \mathrm{S} . \mathrm{cm}^{-1}$. Considerando os valores de condutividade elétrica (CE), é possível obter resultados de sólidos totais dissolvidos (STD) pela razão $\mathrm{STD}_{\text {calculado }} / \mathrm{CE}=0,65$ (APHA, 1995). Os poços $n^{\circ} 1,18,50$ e 53 do aqüífero Cristalino apresentam valores próximos a $1000 \mathrm{mg}$. $\mathrm{dm}^{-3}$, limite a partir do qual as águas podem ser consideradas salobras.

As águas dos Aqüíferos Tubarão, Misto e Não Informado apresentam, respectivamente, valores médios de $\mathrm{pH}$ de 7,52, 7,44 e 7,62 tendendo a alcalino, mas do Cristalino o $\mathrm{pH}$ médio está próximo da neutralidade $(6,70)$. Os valores de potencial de oxido-redução (Eh) apresentam-se oxidantes em praticamente todas os poços desses aqüíferos, excetuando-se o poço n ${ }^{\circ} 12$, que apresentou Eh redutor (-170mV).

No Aqüífero Tubarão ocorrem águas sulfatadas $\mathrm{Na}-\mathrm{Ca}-(\mathrm{Mg})-\mathrm{HCO}_{3}-\mathrm{SO}_{4}$, bicarbonatadas $\mathrm{Na}-\mathrm{Ca}-(\mathrm{Mg})-\mathrm{HCO}_{3}$ e sulfatadas-cloretadas $\mathrm{Na}-(\mathrm{Ca})-\left(\mathrm{HCO}_{3}\right)-\mathrm{SO}_{4}-\mathrm{Cl}$, possuindo maiores concentrações de sódio e concentrações menores de cálcio e magnésio. As águas do Aqüífero Cristalino são predominantemente bicarbonatadas sódicas e cálcicas, $\mathrm{Na}-\mathrm{Ca}-(\mathrm{Mg})-\mathrm{HCO}_{3}$ e Ca-Na-( $\left.\mathrm{Mg}\right)-\mathrm{HCO}_{3}$, podendo ocorrer tipos sulfatados e cloretados: $\mathrm{Ca}-\mathrm{Na}-\left(\mathrm{HCO}_{3}\right)-\mathrm{SO} 4, \mathrm{Na}-\left(\mathrm{HCO}_{3}\right)-\mathrm{SO}_{4}$ e $\mathrm{Na}-(\mathrm{Ca})-\left(\mathrm{SO}_{4}\right)$ $\left(\mathrm{HCO}_{3}\right)-\mathrm{Cl}$. As águas dos poços mistos (Aqüífero Tubarão/Cristalino), bem como daqueles sem aqǘffero informado, representam misturas dos tipos anteriormente mencionados. 
Raphael Hypolito et al.

Tabela 1 - Dados analíticos de poços tubulares de Salto/Indaiatuba.

\begin{tabular}{|c|c|c|c|c|c|c|c|c|c|c|c|c|c|c|}
\hline $\begin{array}{l}\mathrm{N}^{\circ} \\
\text { Poço }\end{array}$ & $\begin{array}{c}\text { Prof. } \\
\text { M }\end{array}$ & $\begin{array}{c}\mathrm{CE} \\
\mu \mathrm{S} \mathrm{cm}\end{array}$ & $\mathrm{pH}$ & $\begin{array}{l}\text { Eh } \\
\mathrm{mV}\end{array}$ & $\begin{array}{c}\mathrm{Cl} \\
\mathrm{mg} \mathrm{dm}^{-3}\end{array}$ & $\begin{array}{c}\mathrm{SO}_{4}{ }^{2} \\
\mathrm{mg} \mathrm{dm}^{-3}\end{array}$ & $\begin{array}{c}F^{F} \\
\mathrm{mg} \mathrm{dm}^{-3}\end{array}$ & $\begin{array}{c}\mathrm{HCO}_{3}{ }^{-} \\
\mathrm{mg} \mathrm{dm}^{-3} \\
\mathrm{CaCO}_{3}\end{array}$ & $\begin{array}{c}\mathrm{Na}^{+} \\
\mathrm{mg} \mathrm{dm}^{-3}\end{array}$ & $\left|\begin{array}{c}\mathrm{Ca}^{2+} \mathrm{mg} \\
\mathrm{dm}^{-3}\end{array}\right|$ & $\begin{array}{c}\mathrm{K}^{+} \\
\mathrm{mg} \mathrm{dm}^{-3}\end{array}$ & $\begin{array}{c}\mathrm{Mg}^{2+} \\
\mathrm{mg} \mathrm{dm}^{-3}\end{array}$ & $\begin{array}{c}\text { Classificação das } \\
\text { Águas }\end{array}$ & $\begin{array}{l}\text { Aqüifero } \\
\text { Explorado }\end{array}$ \\
\hline 1 & 198 & 1302 & 7,30 & +167 & 108,00 & 555,00 & 2,93 & 100,10 & 164,10 & 144,00 & 0,90 & 5,30 & $\mathrm{Ca}-\mathrm{Na}-\mathrm{SO} 4$ & $\mathrm{C}$ \\
\hline 2 & 172 & 261 & 7,40 & +187 & $\mathrm{Nd}$ & $\mathrm{Nd}$ & $\mathrm{Nd}$ & 165,20 & 12,80 & 27,00 & 2,10 & 11,30 & $\mathrm{Ca}-\mathrm{Mg}-\mathrm{HCO} 3$ & TC \\
\hline 3 & 117 & 123 & 6,03 & +221 & 4,00 & 0,60 & 0,06 & 55,10 & 7,90 & 5,40 & 2,30 & 6,70 & $\mathrm{Mg}-\mathrm{Na}-\mathrm{Ca}-\mathrm{HCO} 3$ & $\mathrm{NI}$ \\
\hline 4 & 65 & 285 & 7,61 & +132 & $\mathrm{Nd}$ & 7,80 & 0,68 & 210,30 & 30,50 & 21,00 & 0,90 & 4,50 & Na-Ca-HCO3 & $\mathrm{T}$ \\
\hline 5 & 200 & 331 & 8,10 & +94 & 13,20 & 49,90 & 4,46 & 115,20 & 53,10 & 13,40 & 0,40 & 0,40 & $\mathrm{Na}-\mathrm{Ca}-\mathrm{HCO}-\mathrm{SO} 4$ & T \\
\hline 6 & 216 & 314 & 7,98 & +106 & 9,10 & 40,40 & 4,25 & 115,20 & 46,20 & 15,20 & 0,40 & 0,50 & $\mathrm{Na}-\mathrm{Ca}-\mathrm{HCO}-\mathrm{SO} 4$ & $\mathrm{~T}$ \\
\hline 7 & 300 & 109 & 6,46 & +41 & 0,30 & 0,30 & 0,07 & 70,10 & 7,50 & 4,30 & 1,80 & 3,60 & $\mathrm{Na}-\mathrm{Mg}-\mathrm{Ca}-\mathrm{HCO} 3$ & C \\
\hline 8 & 160 & 432 & 7,39 & +126 & 20,90 & 82,20 & 2,50 & 145,20 & 69,30 & 15,00 & 0,60 & 1,50 & $\mathrm{Na}-\mathrm{HCO} 3-\mathrm{SO} 4$ & C \\
\hline 9 & 182 & 367 & 7,38 & +93 & 15,90 & 68,40 & 3,31 & 180,20 & 74,20 & 18,00 & 0,50 & 1,00 & $\mathrm{Na}-\mathrm{HCO} 3-\mathrm{SO} 4$ & C \\
\hline 10 & 54 & 207 & 6,93 & +196 & $\mathrm{Nd}$ & $\mathrm{Nd}$ & $\mathrm{Nd}$ & 115,20 & 17,80 & 15,60 & 2,00 & 7,40 & $\mathrm{Ca}-\mathrm{Na}-\mathrm{Mg}-\mathrm{HCO} 3$ & C \\
\hline 11 & 150 & 290 & 7,16 & +139 & 9,90 & 40,10 & 0,29 & 100,10 & 24,80 & 15,30 & 2,10 & 8,80 & $\mathrm{Na}-\mathrm{Ca}-\mathrm{Mg}-\mathrm{HCO} 3-\mathrm{SO} 4$ & T \\
\hline 12 & 80 & 822 & 9,89 & -170 & 64,20 & 258,90 & 1,95 & 25,00 & 140,90 & 28,90 & 0,60 & 18,20 & $\mathrm{Na}-\mathrm{SO} 4-\mathrm{Cl}$ & $\mathrm{NI}$ \\
\hline 13 & 300 & 243 & 7,97 & +206 & $\mathrm{Nd}$ & nd & 1,06 & 140,20 & 32,20 & 16,60 & 1,40 & 5,10 & $\mathrm{Na}-\mathrm{Ca}-\mathrm{HCO} 3$ & C \\
\hline 14 & 175 & 244 & 6,36 & +252 & $\mathrm{Nd}$ & nd & 1,86 & 95,10 & 16,80 & 18,80 & 2,50 & 1,40 & $\mathrm{Ca}-\mathrm{Na}-\mathrm{HCO} 3$ & c \\
\hline 15 & 142 & 430 & 6,48 & +132 & 7,70 & 13,30 & 0,71 & 210,30 & 18,10 & 60,00 & 7,90 & 6,20 & $\mathrm{Ca}-\mathrm{HCO} 3$ & C \\
\hline 16 & 450 & 375 & 6,33 & +34 & 4,00 & nd & 1,08 & 240,30 & 54,30 & 31,00 & 1,60 & 2,60 & $\mathrm{Na}-\mathrm{Ca}-\mathrm{HCO} 3$ & c \\
\hline 17 & 138 & 502 & 6,58 & +258 & 3,90 & 15,10 & $\mathrm{Nd}$ & 130,20 & 27,60 & 20,00 & 1,80 & 6,40 & $\mathrm{Na}-\mathrm{Ca}-\mathrm{HCO} 3$ & C \\
\hline 18 & 120 & 1474 & 6,32 & +232 & 125,00 & 590,00 & 2,67 & 35,00 & 166,00 & 108,00 & 1,10 & 11,10 & $\mathrm{Na}-\mathrm{Ca}-\mathrm{SO} 4-\mathrm{Cl}$ & c \\
\hline 19 & 138 & 252 & 7,20 & +242 & 5,00 & 24,80 & $\mathrm{Nd}$ & 120,20 & 13,20 & 25,50 & 2,30 & 5,70 & $\mathrm{Ca}-\mathrm{Na}-\mathrm{HCO} 3-\mathrm{SO} 4$ & c \\
\hline 20 & & 856 & 7,45 & +189 & 70,00 & 288,00 & 1,95 & 70,10 & 102,00 & 53,10 & 1,60 & 11,30 & $\mathrm{Na}-\mathrm{Ca}-\mathrm{SO} 4-\mathrm{Cl}$ & $T$ \\
\hline 21 & 150 & 322 & 7,84 & +243 & 23,90 & 44,60 & 3,74 & 80,10 & 71,90 & 3,00 & 0,90 & 0,30 & $\mathrm{Na}-\mathrm{HCO} 3-\mathrm{SO} 4-\mathrm{Cl}$ & $\begin{array}{ccl}T \\
\end{array}$ \\
\hline 22 & 150 & 196 & 6,87 & +290 & 2,60 & 10,50 & 1,27 & 105,10 & 20,10 & 15,80 & 2,10 & 4,50 & $\mathrm{Na}-\mathrm{Ca}-\mathrm{HCO} 3$ & TC \\
\hline 23 & 167 & 158 & 6,88 & +295 & $\mathrm{Nd}$ & $\mathrm{Nd}$ & $\mathrm{Nd}$ & 85,10 & 9,60 & 17,10 & 1,80 & 4,40 & Ca-Na-Mg-HCO3 & TC \\
\hline 24 & 40 & 69 & 5,19 & +300 & 7,60 & 0,20 & $\mathrm{Nd}$ & 15,00 & 6,30 & 0,10 & 8,50 & 0,60 & Na-K-HCO3-Cl & C \\
\hline 25 & 160 & 124 & 6,87 & +300 & 0,50 & 1,30 & 0,71 & 50,10 & 12,40 & 3,00 & 0,30 & 5,60 & $\mathrm{Na}-\mathrm{Mg}-\mathrm{HCO} 3$ & C \\
\hline 26 & 150 & 215 & 7,61 & +258 & 0,20 & 1,50 & 0,07 & 170,20 & 9,60 & 10,90 & 2,70 & 10,00 & $\mathrm{Mg}-\mathrm{Ca}-\mathrm{HCO} 3$ & $\mathrm{~T}$ \\
\hline 27 & 276 & 313 & 8,06 & +220 & 5,20 & 25,50 & 0,91 & 225,30 & 65,50 & 5,30 & 0,90 & 2,30 & $\mathrm{Na}-\mathrm{HCO} 3$ & TC \\
\hline 28 & 175 & 241 & 7,27 & +332 & 1,60 & 4,90 & 0,54 & 145,20 & 36,40 & 5,50 & 1,20 & 3,20 & $\mathrm{Na}-\mathrm{HCO} 3$ & $T$ \\
\hline 29 & 170 & 361 & 7,94 & +248 & 7,70 & 74,30 & 3,58 & 95,10 & 61,60 & 17,10 & 0,20 & 1,20 & $\mathrm{Na}-\mathrm{Ca}-\mathrm{HCO} 3-\mathrm{SO} 4$ & TC \\
\hline 30 & 180 & 337 & 7,87 & +261 & 2,40 & 14,00 & 3,14 & 215,30 & 59,90 & 13,90 & 0,20 & 1,20 & $\mathrm{Na}-\mathrm{HCO} 3$ & $\mathrm{C}$ \\
\hline 31 & 282 & 293 & 8,56 & +213 & 7,20 & 10,60 & 6,95 & 140,20 & 71,10 & 3,30 & 0,20 & 0,10 & $\mathrm{Na}-\mathrm{HCO} 3$ & TC \\
\hline 32 & 150 & 244 & 6,60 & & 3,00 & 0,00 & 0,00 & 122,00 & 18,40 & 29,60 & 4,70 & 0,50 & $\mathrm{Ca}-\mathrm{Na}-\mathrm{HCO} 3$ & C \\
\hline 33 & 111 & & 5,87 & & 0,35 & 3,00 & 0,01 & 10,00 & & & & & & C \\
\hline 34 & 192 & & 8,60 & & 6,00 & & 0,10 & 122,00 & & & & & & $T$ \\
\hline 35 & 267 & & 6,53 & & 18,00 & & 0,10 & 8,22 & & & & & & TC \\
\hline 36 & 135 & & 7,30 & & 23,00 & & 0,13 & 80,00 & & & & & & TC \\
\hline 37 & 186 & & 6,70 & & 21,00 & & 0,13 & 118,00 & & & & & & TC \\
\hline 38 & 150 & & 6,40 & & & & 0,15 & 66,00 & & & & & & $T$ \\
\hline 39 & 250 & & 7,28 & & & $<1$ & 0,15 & & & & & & & C \\
\hline 40 & 104 & & 7,39 & & 0,20 & $<1$ & 0,17 & & 15,40 & & & & & $T$ \\
\hline 41 & 206 & 111 & 6,50 & & 6,00 & 0,00 & 0,20 & 60,00 & 11,60 & 19,20 & 2,30 & 0,90 & $\mathrm{Ca}-\mathrm{Na}-\mathrm{HCO} 3$ & $\mathrm{C}$ \\
\hline 42 & & & 7,50 & & 16,00 & & 0,20 & 85,00 & & & & & & TC \\
\hline 43 & & & 8,10 & & 13,00 & 8,20 & 0,27 & & 6,10 & & & & & $T$ \\
\hline 44 & & & 7,80 & & 15,00 & & 0,32 & 86,00 & & & & & & T \\
\hline 45 & 96 & & 7,80 & & 7,00 & 12,00 & 0,33 & 130,00 & & 6,48 & & 6,29 & & T \\
\hline 46 & 91 & & 6,70 & & 22,00 & & 0,37 & 108,00 & & & & & & C \\
\hline 47 & 150 & & 7,80 & & 5,90 & & 0,50 & 172,30 & & 19,90 & & & & TC \\
\hline 48 & 150 & & 7,40 & & 12,00 & & 0,67 & 158,40 & & 17,10 & & & & TC \\
\hline 49 & 150 & 181 & 8,40 & & 5,00 & 2,30 & 0,80 & 82,00 & 14,80 & 23,20 & 3,90 & 0,50 & $\mathrm{Ca}-\mathrm{Na}-\mathrm{HCO} 3$ & TC \\
\hline 50 & & 1868 & 6,05 & & 314,00 & 81,86 & 0,82 & 90,00 & & & & & & C \\
\hline 51 & & 448 & 6,64 & & 24,00 & & 0,94 & 92,00 & & & & & & $\mathrm{C}$ \\
\hline 52 & 124 & 894 & 6,62 & & 104,00 & 36,82 & 0,97 & 124,00 & & & & & & C \\
\hline 53 & 150 & 1611 & 6,36 & & 236,00 & 91,60 & 1,12 & 148,00 & & & & & & C \\
\hline 54 & 120 & 675 & 6,78 & & 46,00 & 50,63 & 1,40 & 138,00 & & & & & & C \\
\hline 55 & 150 & 391 & 6,91 & & 10,00 & 8,48 & 1,64 & 134,00 & & & & & & C \\
\hline 56 & 152 & & 7,50 & & 17,90 & 16,00 & 1,83 & 154,00 & & & & & & C \\
\hline 57 & 130 & & 7,30 & & 170,00 & 110,00 & 1,85 & 184,00 & & & & & & c \\
\hline 58 & 270 & & 6,60 & & 0,40 & 1,55 & 1,91 & & 163,00 & & & & & C \\
\hline 59 & 150 & & 8,00 & & 10,55 & 44,30 & 3,10 & & 25,40 & & & & & T \\
\hline 60 & 112 & 260 & 6,80 & & 6,00 & 49,00 & 4,00 & 100,00 & 135,00 & 32,00 & 3,00 & 1,70 & $\mathrm{Na}-\mathrm{Ca}-\mathrm{HCO} 3-\mathrm{SO} 4$ & $T$ \\
\hline 61 & & & 6,60 & & - & & 0,00 & 103,00 & & & & & & $\begin{array}{ccl}T \\
\end{array}$ \\
\hline 62 & 258 & & 7,90 & & 5,80 & & 0,00 & 420,00 & & & & & & TC \\
\hline 63 & 120 & & 6,40 & & & & 0,23 & & & & & & & TC \\
\hline 64 & 132 & & 6,25 & & & & 0,90 & & & & & & & C \\
\hline 65 & 150 & & 7,60 & & 24,92 & 76,08 & 0,00 & & 50,21 & & & & & $\mathrm{NI}$ \\
\hline 66 & 190 & 166 & 6,76 & & $<1$ & $<1$ & 0,22 & 84,00 & & & & & & $\mathrm{~T}$ \\
\hline 67 & 202 & & 4,65 & & $<1$ & $<7$ & 0,95 & & 125,00 & & & & & c \\
\hline 68 & 150 & 153 & 7,00 & & & 5,00 & 0,30 & 250,00 & & & & & & $\mathrm{C}$ \\
\hline
\end{tabular}

Nd: não detectado.

Aqüífero Explorado: C-Cristalino; TC: Misto - Tubarão/Cristalino; T: Tubarão; NI: Não Informado. 
Considerando os cátions, os Aqüíferos Tubarão, Cristalino, Misto e Não Informado apresentaram maiores concentrações relativas de $\mathrm{Na}^{+}$(médias respectivas de $56,61 \mathrm{mg} . \mathrm{dm}^{-3}$, 47,38 mg.dm ${ }^{-3}, 36,50 \mathrm{mg} \cdot \mathrm{dm}^{-3}$ e 74,40 mg.dm ${ }^{-3}$ ), seguidas de $\mathrm{Ca}^{2+}\left(18,82 \mathrm{mg} \cdot \mathrm{dm}^{-3}, 32,71 \mathrm{mg} \cdot \mathrm{dm}^{-3}, 15,54 \mathrm{mg} \cdot \mathrm{dm}^{-3} \mathrm{e}\right.$ $\left.17,15 \mathrm{mg} \cdot \mathrm{dm}^{-3}\right)$. Presentes em menores concentrações, os valores médios de $\mathrm{Mg}^{2+}$ e $\mathrm{K}^{+}$para os aqüíferos mencionados são, respectivamente, 4,52 e 1,47 mg.dm ${ }^{-3}, 4,08$ e 2,38 mg.dm ${ }^{-3}, 3,47$ e 1,60 mg.dm ${ }^{-3}$ e 1,45 e 12,45 mg.dm ${ }^{-3}$.

Entre os ânions, predomina $\mathrm{HCO}_{3}^{-}$nas águas dos aqüíferos, com médias muito próximas, em torno de $125 \mathrm{mg} \mathrm{dm}^{-3}$.

Os teores de sulfato nas águas apresentam-se muito variáveis no Aqüífero Tubarão (1,50 a 288,00 $\left.\mathrm{mg} \cdot \mathrm{dm}^{-3}\right)$, Cristalino $\left(0,00\right.$ a $\left.590,00 \mathrm{mg}^{\mathrm{dm}} \mathrm{dm}^{-3}\right)$, Misto (2,30 a 74,30 $\left.\mathrm{mg} \cdot \mathrm{dm}^{-3}\right)$ e Não Informado $\left(0,60\right.$ a $\left.258,90 \mathrm{mg} \cdot \mathrm{dm}^{-3}\right)$, apresentando médias elevadas de 58,47 mg.dm ${ }^{-3}, 113,72 \mathrm{mg} \cdot \mathrm{dm}^{-3}, 24,64 \mathrm{mg} \cdot \mathrm{dm}^{-3}$ e $129,45 \mathrm{mg} \cdot \mathrm{dm}^{-3}$, respectivamente. Excedem o padrão de potabilidade $\left(250 \mathrm{mg} . \mathrm{dm}^{-3}\right)$ em dois poços $\left(\mathrm{n}^{\circ} 1\right.$ e 18) do Cristalino, um poço do Tubarão $\left(n^{\circ} 20\right)$ e um poço de aqüífero Não Informado $\left(n^{\circ} 12\right)$.

As concentrações médias de cloreto são, respectivamente, de $16,74 \mathrm{mg} \cdot \mathrm{dm}^{-3}, 23,40 \mathrm{mg} \cdot \mathrm{dm}^{-3}$ e $5,54 \mathrm{mg} \cdot \mathrm{dm}^{-3} \mathrm{e}$ $34,10 \mathrm{mg} \cdot \mathrm{dm}^{-3}$ para os aqüíferos Tubarão, Cristalino, Misto e Não Informado, podendo ocorrer valores muito elevados, pontualmente, como nos poços $\mathrm{n}^{\circ} 20\left(70 \mathrm{mg} \cdot \mathrm{dm}^{-3}\right)$ do Tubarão e $\mathrm{n}^{\circ} 1$ e 18 (108 e 125 mg.dm $\left.{ }^{-3}\right)$ do Cristalino.

Analisando os teores de fluoreto de 68 poços de Salto e Indaiatuba, 19 poços (aproximadamente 28\%) apresentam valores superiores a $1,50 \mathrm{mg} \cdot \mathrm{dm}^{-3}$, limite de potabilidade. A concentração média de fluoreto nos poços é de $1,25 \mathrm{mg} . \mathrm{dm}^{-3}$, variando entre $0,00 \mathrm{a} 6,95 \mathrm{mg} \cdot \mathrm{dm}^{-3}$. Os teores médios de $\mathrm{F}^{-}$para os aqüíferos Tubarão, Cristalino, Misto (Tubarão/Cristalino) e Não Informado são, respectivamente, $1,37 \mathrm{mg} \mathrm{dm}^{-3}$ (32 poços), 1,26 mg.dm ${ }^{-3}$ (18 poços), $1,19 \mathrm{mg} \cdot \mathrm{dm}^{-3}$ (15 poços) e 1,01 mg.dm ${ }^{-3}$ (3 poços).

A distribuição espacial dos poços e a variação das concentrações de fluoreto na região estão representadas na Figura 2. Os poços com maior concentração de $\mathrm{F}^{-}$na água se distribuem, preferencialmente, em três zonas da área estudada. Uma dessas zonas está localizada a oeste da cidade de Salto, próxima ao Rio Tietê, incluindo os poços $n^{\circ} 1,12,18$ e 20 do Tubarão e Tubarão/Cristalino. A segunda zona está localizada na porção centro-norte de Salto e sudoeste de Indaiatuba e inclui os poços $\mathrm{n}^{\circ}$ 5, 6, 8, 9; 21, 29, 30, 31, 59 e 60 do Tubarão e Tubarão/Cristalino. A última zona está situada na porção sudeste de Salto, onde afloram granitóides, incluindo os poços $n^{\circ} 14,55,56,57$ e 58 do Cristalino. Nessas zonas, observa-se uma associação dos poços com alto teor de $\mathrm{F}^{-}$às drenagens que estão, preferencialmente, encaixadas em estruturas NW e, secundariamente em estruturas NS e NE (Figuras 1 e 2). Nos Grupos Tubarão e Passa Dois, o IPT (1986) constatou, também, teores superiores a $1,5 \mathrm{mg} \cdot \mathrm{dm}^{-3} \mathrm{de} \mathrm{F}^{-}$em 17 poços, mas, de forma geral, são poucos os trabalhos que tratam da ocorrência do flúor nos Aqüíferos Tubarão e Cristalino, podendo ser destacados os de Pinheiro et al (1965) e Ribeiro (1992).

Considerando os 19 poços com teor elevado de $\mathrm{F}^{-}\left(>1,5 \mathrm{mg} \cdot \mathrm{dm}^{-3}\right)$ levantados nesse trabalho, constata-se que no Aqüífero Cristalino (10 poços) a concentração média é de 2,36 $\mathrm{mg} \mathrm{dm}^{-3}$, enquanto nos poços dos Aqüíferos Tubarão (6 poços) e Tubarão/Cristalino ( 2 poços) as médias são mais altas, 3,58 e 5,27 mg.dm ${ }^{-3}$, respectivamente. Há um poço ( $\left.{ }^{\circ} 12\right)$ com valor de $1,95 \mathrm{mg} \cdot \mathrm{dm}^{-3} \mathrm{de} \mathrm{F}^{-}$, cujo aqüífero não foi identificado. O valor mais elevado de $\mathrm{F}^{-}$foi de $6,95 \mathrm{mg} . \mathrm{dm}^{-3}$ constatado em Aqüífero Misto Tubarão/Cristalino.

$\mathrm{O}$ valor médio do $\mathrm{pH}$ das águas de poços com dados de concentração de $\mathrm{F}^{-}$é de 7,13 (68 poços). Considerando os 19 poços com teores de $\mathrm{F}^{-}$acima de $1,50 \mathrm{mg} \cdot \mathrm{dm}^{-3}$, o pH médio da água apresenta-se mais elevado, 7,55, variando de 6,32 a 9,89.

Os dados analíticos de águas de poços cacimba da região são apresentados na Tabela 2.

Os poços cacimba que captam água do Aqüífero Freático, constituído pelo manto de alteração e pelo solo, apresentam profundidades variando entre 10 e $30 \mathrm{~m}$ e valor médio de $19 \mathrm{~m}$. Suas águas possuem condutividade elétrica média de $117 \mu{\mathrm{S} . \mathrm{cm}^{-1}}^{\mathrm{e}}$ valores de $\mathrm{pH}$ variando entre de 4,99 e7,69, com valor médio de 6,00 . O potencial de óxido-redução dessas águas é oxidante, com valor médio de $+223 \mathrm{mV}$.

As águas do Aqüífero Fréatico classificam-se como bicarbonatadas cálcicas, sódicas ou magnesianas, ocorrendo, também, águas mistas $\mathrm{HCO}_{3}-\mathrm{Cl}$ e $\mathrm{HCO}_{3}-\mathrm{SO}_{4}$ com proporções variáveis de sódio e magnésio como cátions dominantes. $\mathrm{O}$ teor médio de fluoreto é $0,10 \mathrm{mg} \cdot \mathrm{dm}^{-3}$, variando de $0,00 \mathrm{a}$ $0,37 \mathrm{mg} \cdot \mathrm{dm}^{-3}$.

Na Tabela 3, são apresentados dados de teor de flúor e mineralogia de rochas sedimentares do Subgrupo Itararé e de granitos coletados na área de estudo (Figura 1).

As amostras de rochas sedimentares (SED-4e, SED-5b e SED-2Ae) do Subgrupo Itararé apresentam teores de flúor variando entre 839 e $1227 \mathrm{ppm}$. Os resultados de difração de Raios X das amostras analisadas indicam a presença de esmectita, vermiculita, clorita, caulinita e mica na fração argila.

Os granitóides (GR-3D, GR-53, GR-6, GR-10) correspondem a amostras porfiróides, isotrópicas, de granulação fina a grossa, constituídos, essencialmente, por quartzo (35-39\% vol.), feldspato potássico (28-43\% vol.), plagioclásio (16-27\% vol.) e biotita (2-11,8\%), tendo como minerais acessórios titanita, zircão, fluorita, calcita, magnetita, pirita e minerais opacos (Tabela 3). As amostras estudadas apresentam porcentagens pouco mais elevadas de biotita em comparação às médias obtidas por Galembeck (1997). Os teores de flúor total obtidos nos granitóides variaram entre 975 e 1878 ppm. 
Raphael Hypolito et al.

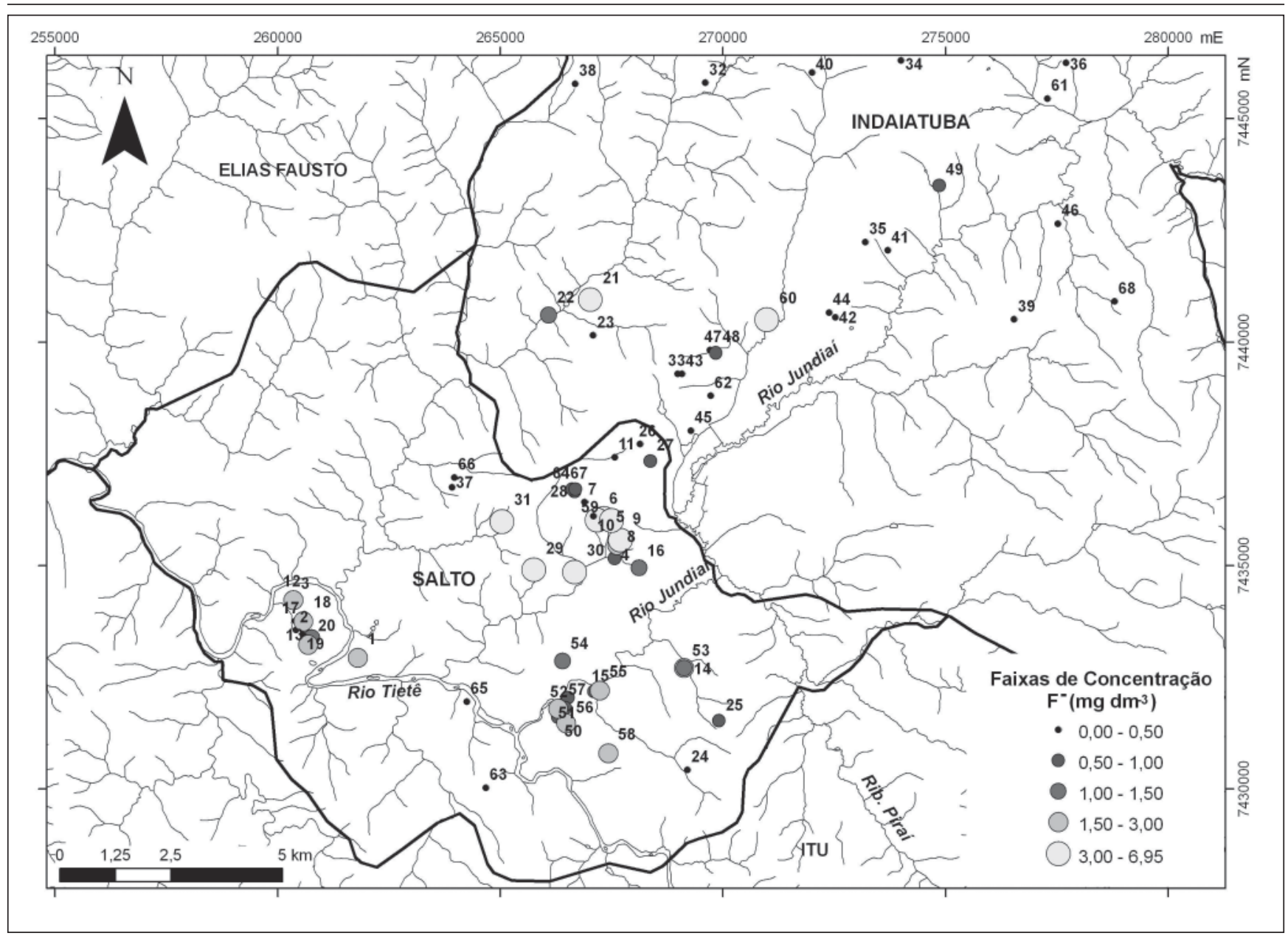

Figura 2 - Concentração de fluoreto em poços tubulares de Salto e sul de Indaiatuba (SP).

\section{Discussões}

Existem dois mecanismos que podem enriquecer aqüíferos em $\mathrm{F}^{-}$. Um primeiro mecanismo provoca o enriquecimento da água nesse íon a partir da liberação de flúor presente em minerais ricos nesse elemento (Ampabire et al., 1997; Banks et al., 1998; Kim \& Jeong, 2005; Chae et al., 2007; Nanni, 2008). Um segundo mecanismo está associado à percolação de fluidos hidrotermais ricos em flúor (Allmann \& Koritnig, 1969; Fraga, 1992; Ribeiro, 1992).

O mineral que possui maior quantidade de flúor na estrutura é a fluorita $\left(\mathrm{CaF}_{2}\right)$ e, secundariamente, a villamita $(\mathrm{NaF})$ e a criolita $\left(\mathrm{Na}_{3} \mathrm{AlF}{ }_{6}\right)$. Na fluorapatita/fosforita $\left(\mathrm{Ca}_{5}\left(\mathrm{PO}_{4}\right)_{3}(\mathrm{~F}, \mathrm{OH})\right.$, nos hidroxi-silicatos e hidroxi-alumino-silicatos, como os anfibólios e as micas e, nos argilominerais como illita, esmectita, clorita, $\mathrm{OH}^{-}$pode ser substituído por $\mathrm{F}^{-}$devido à similaridade de seus raios iônicos $\left(\mathrm{OH}^{-}=1,32 \AA\right.$ e $\mathrm{F}^{-}=1,36 \AA$ ) (Allmann \& Koritnig, 1969; Boyle, 1992; Ampabire et al., 1997 Banks et al., 1998; Kim \& Jeong, 2005; Panagoulias \& Silva Filho, 2006; Chea et al., 2007). Em vários estudos, a presença de F-, nas águas subterrâneas, é atribuída à solubilização de minerais ricos em flúor presentes nas rochas, manto de alteração, veios ou preenchendo fraturas (Apambire et al., 1997; Kim \& Jeong, 2005; Chae et al., 2006; Mariomon, 2006; Panagoulias \& Silva Filho, 2006; Silvério da Silva et al., 2006; Velásques et al., 2006; Chae et al., 2007; Kern et al. , 2008).

No Aqüífero Cristalino da região estudada, a fluorita e a apatita não podem ser consideras as fontes primárias de flúor, uma vez que ocorrem como acessórios nos granitóides (Tabela 3). Também não há presença de villamita e criolita nessas rochas. Um aporte de flúor a partir dessas rochas poderia ser associado à presença de biotita rica em flúor que ocorre nos granitóides, com teores de flúor variando entre, 0,21 a 1,33, média 0,82, em porcentagem em peso (Gallembeck, 1997, Gallembeck et al., 1997) e concentrações volumétricas variando entre $2 \%$ e $11,8 \%$, média $5,95 \%$, nas amostras estudadas (amostras GR-6, GR-5E, GR-10 e GR-3D, Tabela $3)$. Entretanto, os granitóides possuem pequenas porcentagens de máficos.

No Aqüífero Tubarão, as amostras de rochas sedimentares coletadas na área não apresentam fluorita ou apatita como constituintes mineralógicos. Entretanto, detectou-se a presença de argilominerais (esmectita, vermiculita, caulinita, illita) e 
Fluoreto nas águas subterrâneas dos aqüíferos Tubarão e Cristalino, região de Salto-Indaiatuba (SP)

\begin{tabular}{|c|c|c|c|c|c|c|c|c|c|c|c|c|c|}
\hline $\mathbf{N}^{\circ}$ Poço & $\begin{array}{c}\text { Prof. } \\
\text { m }\end{array}$ & $\begin{array}{c}\text { CE } \\
\mu \mathrm{S} \mathrm{cm} \mathrm{cm}^{-1}\end{array}$ & $\mathrm{pH}$ & $\begin{array}{l}\text { Eh } \\
\mathrm{mV}\end{array}$ & $\begin{array}{c}\mathrm{Cl} \\
\mathrm{mg} \mathrm{dm}^{-3}\end{array}$ & $\begin{array}{c}\mathrm{SO}_{4}{ }^{2} \\
\mathrm{mg} \mathrm{dm}^{-3}\end{array}$ & $\begin{array}{c}F \\
m g ~ d m\end{array}$ & $\begin{array}{c}\mathrm{Alc}_{\mathrm{HCO}_{3}^{-}}^{-} \\
\mathrm{mg} \mathrm{dm}^{-3} \\
\mathrm{CaCO}_{3}\end{array}$ & $\begin{array}{c}\mathrm{Na}^{+} \\
\mathrm{mg} \mathrm{dm}\end{array}$ & $\begin{array}{c}\mathrm{Ca}^{2+} \\
\mathrm{mg} \mathrm{dm}\end{array}$ & $\begin{array}{c}\mathrm{K}^{+} \\
\mathrm{mg} \mathrm{dm}\end{array}$ & $\begin{array}{c}\mathrm{Mg}^{2+} \\
\mathrm{mg} \mathrm{dm}^{-}\end{array}$ & Classificação das Águas \\
\hline PC01 & 12 & 197 & 5,95 & 248 & 17,10 & 4,16 & 0,09 & 30,52 & 15,35 & 5,68 & 3,94 & 14,02 & Mg-Na-HCO3-Cl \\
\hline $\mathrm{PC} 02$ & 10 & 208 & 6,80 & 94 & 19,09 & 17,20 & 0,18 & 36,62 & 28,29 & 5,31 & 2,11 & 7,53 & $\mathrm{Na}-\mathrm{Mg}-\mathrm{HCO} 3-\mathrm{SO} 4-\mathrm{Cl}$ \\
\hline PC4a-1 & 23 & 402 & 7,10 & 88 & 0,40 & 9,55 & 0,21 & 12,21 & 27,27 & 30,77 & 7,12 & 8,25 & $\mathrm{Na}-\mathrm{Mg}-\mathrm{Ca}-\mathrm{HCO} 3-\mathrm{SO} 4$ \\
\hline PC4b-1 & 22 & 65 & 6,03 & 172 & 0,96 & 2,11 & 0,07 & 15,26 & 4,61 & 2,99 & 3,81 & 2,26 & $\mathrm{Na}-\mathrm{Ca}-\mathrm{HCO} 3$ \\
\hline PC05 & & 40 & 5,62 & 195 & 0,88 & 0,17 & 0,10 & 6,10 & 1,70 & 2,01 & 0,90 & 0,27 & $\mathrm{Na}-\mathrm{Ca}-\mathrm{HCO} 3$ \\
\hline $\mathrm{PC} 06$ & & 37 & 5,22 & 217 & 1,06 & 0,12 & 0,03 & 6,10 & 2,42 & 0,28 & 0,81 & 0,74 & $\mathrm{Na}-\mathrm{HCO} 3$ \\
\hline $\mathrm{PC} 07$ & & 69 & 4,99 & 222 & 4,67 & 0,09 & 0,04 & 3,05 & 3,60 & 0,94 & 3,23 & 2,08 & $\mathrm{Na}-\mathrm{HCO} 3-\mathrm{Cl}$ \\
\hline PC09 & & 49 & 5,88 & 139 & 0,43 & 0,17 & $\mathrm{Nd}$ & 170,89 & 2,95 & 3,43 & 2,11 & 0,64 & Ca-HCO3 \\
\hline PC10 & & 44 & 5,69 & 182 & 0,78 & 0,08 & 0,05 & 9,15 & 1,58 & 2,32 & 1,97 & 0,44 & $\mathrm{Ca}-\mathrm{HCO} 3$ \\
\hline PC11-1 & & 171 & 5,41 & 173 & 7,45 & 2,67 & 0,37 & 125,12 & 8,69 & 5,08 & 2,96 & 10,51 & $\mathrm{Mg}-\mathrm{Na}-\mathrm{HCO} 3$ \\
\hline PC18-1 & & 15 & 5,23 & 217 & 0,66 & 0,33 & 0,04 & 10,01 & 1,90 & 0,18 & 0,27 & 0,14 & $\mathrm{Na}-\mathrm{HCO} 3$ \\
\hline PC19 & 12 & 79 & 5,51 & 233 & 8,78 & 1,64 & 0,06 & 9,15 & 5,90 & 2,03 & 3,13 & 3,43 & $\mathrm{Mg}-\mathrm{Na}-\mathrm{Cl}$ \\
\hline PC20-1 & 21 & 323 & 7,62 & 705 & 5,23 & 1,26 & 0,21 & 158,68 & 26,66 & 10,75 & 4,02 & 18,50 & $\mathrm{Mg}-\mathrm{Na}-\mathrm{HCO} 3$ \\
\hline $\mathrm{PC} 21$ & 30 & 435 & 7,69 & 189 & 26,86 & 14,68 & 0,10 & 146,48 & 45,88 & 16,84 & 4,72 & 20,43 & $\mathrm{Mg}-\mathrm{Na}-\mathrm{Ca}-\mathrm{HCO} 3$ \\
\hline $\mathrm{PC} 22$ & & 33 & 5,35 & 231 & 1,34 & 0,16 & 0,03 & 6,10 & 2,80 & 1,05 & 1,74 & 0,47 & $\mathrm{Na}-\mathrm{HCO} 3$ \\
\hline PC23-2 & & 54 & 5,72 & 256 & $\mathrm{Nd}$ & $\mathrm{Nd}$ & $\mathrm{Nd}$ & 15,01 & 2,46 & 1,40 & 5,10 & 2,72 & $\mathrm{Mg}-\mathrm{Na}-\mathrm{HCO} 3$ \\
\hline PC24 & 16 & 26 & 5,53 & 234 & 0,50 & 0,16 & 0,03 & 6,10 & 1,40 & 1,10 & 1,49 & 0,55 & $\mathrm{Na}-\mathrm{Ca}-\mathrm{HCO} 3$ \\
\hline PC25 & 26 & 40 & 6,12 & 221 & 0,31 & 0,34 & 0,03 & 15,26 & 0,79 & 3,64 & 2,63 & 0,33 & $\mathrm{Ca}-\mathrm{HCO} 3$ \\
\hline PC31 & & 59 & 6,45 & 273 & $\mathrm{Nd}$ & $\mathrm{Nd}$ & $\mathrm{Nd}$ & 30,03 & 0,97 & 9,90 & 1,57 & 0,26 & $\mathrm{Ca}-\mathrm{HCO} 3$ \\
\hline PC32 & & 49 & 5,76 & 275 & $\mathrm{Nd}$ & $\mathrm{Nd}$ & $\mathrm{Nd}$ & 35,03 & 5,29 & 1,80 & 2,82 & 1,19 & $\mathrm{Na}-\mathrm{HCO} 3$ \\
\hline PC33 & & 23 & 5,77 & 275 & $\mathrm{Nd}$ & $\mathrm{Nd}$ & $\mathrm{Nd}$ & 5,00 & 2,01 & 2,70 & 2,16 & 1,00 & $\mathrm{Na}-\mathrm{CaCl}-\mathrm{HCO} 3$ \\
\hline PC45 & 22 & 146 & 6,48 & 85 & 12,40 & $\mathrm{Nd}$ & $\mathrm{Nd}$ & 60,06 & 9,62 & 2,22 & 3,96 & 8,03 & $\mathrm{Mg}-\mathrm{Na}-\mathrm{K}-\mathrm{Cl}-\mathrm{HCO} 3$ \\
\hline
\end{tabular}

$\mathrm{Nd}$ : não detectado

Tabela 3 - Composição mineralógica e teor de flúor total de amostras de rocha da área estudada.

\begin{tabular}{|c|c|c|c|}
\hline Amostra & Litotipo & Mineralogia & $F(p p m)$ \\
\hline SED-4e & Folhelho cinza esverdeado & $\begin{array}{l}\text { Fração Argila: illita, vermiculita. Fração Silte Fino: quartzo, microclínio, } \\
\text { mica, hematita. }\end{array}$ & 1227 \\
\hline SED-5b & Siltito cinza claro & $\begin{array}{l}\text { Fração Argila: Caulim, mica, esmectita, clorita, dolomita, interestratificado } \\
(24 A, 15 A, 9 A) \text {. Fração Silte Fino: quartzo, albita, microclínio, mica. }\end{array}$ & 839 \\
\hline SED-2Ae & Argilito siltoso maciço ocre & $\begin{array}{l}\text { Fração Argila (42,95\%): mica, caulinita, esmectita, goethita. Fração Silte } \\
\text { Fino }(43,35 \%) \text { : quartzo, caulinita, mica, microclínio. }\end{array}$ & 1097 \\
\hline GR-6 & Granitóide porfiróide róseo & $\begin{array}{l}\text { Quartzo }(35 \%) \text {, feldspato potássico }(30 \%) \text {, plagioclásio } \mathrm{An}_{10}(27 \%) \text {, biotita } \\
(5 \%) \text {. Acessórios: titanita }(2 \%) \text {, magnetita+opacos (1\%). Traços: zircão, } \\
\text { fluorita. }\end{array}$ & 975 \\
\hline GR-5E & Granitóide porfiróide róseo & $\begin{array}{l}\text { Quartzo }(35 \%) \text {, feldspato potássico }(38 \%) \text {, plagioclásio } \mathrm{An}_{20}(20 \%) \text {, biotita } \\
(5 \%) \text {. Acessórios: titanita }(0,7 \%) \text {, magnetita+ minerais opacos }(0,6 \%) \text {. }\end{array}$ & 1405 \\
\hline GR-10 & Granitóide porfiróide vermelho & $\begin{array}{l}\text { Quartzo }(37 \%) \text {, feldespato potássico }(43 \%) \text {, plagioclásio } \mathrm{An}_{10}(16 \%) \text {, biotita } \\
(2 \%) \text {. Acessórios: magnetita }(0,5 \%) \text {, pirita }(0,5 \%) \text {. Traços: titanita, apatita, } \\
\text { calcita. }\end{array}$ & 1104 \\
\hline GR-3D & Granitóide porfiróide vermelho & $\begin{array}{l}\text { Quartzo }(39 \%) \text {, feldespato potássico }(28,7 \%) \text {, plagioclásio }(17,3 \%) \text {, biotita } \\
(11,8 \%) \text {. Acessórios: magnetita }(0,8 \%) \text {, titanita }(1,6 \%) \text {, pirita }(0,8 \%) \text {. }\end{array}$ & 1878 \\
\hline
\end{tabular}

micas que, potencialmente, podem ser portadoras de flúor. Em análises químicas de rocha total de um siltito, um folhelho e um argilito (Tabela 3), os valores de flúor obtidos variaram entre 839 e 1227 ppm, mostrando altos teores desse elemento.

Na porção sul de Indaiatuba, Florêncio (2000) também determinou altos teores de flúor total em um argilito (390 ppm) e um ritmito (450 ppm) constituídos por quartzo, caulinita, illita, esmectita, clorita, feldspato e óxidos-hidróxidos de ferro. A autora associou a presença de flúor às esmectitas.

Segundo Ramos e Formoso (1975), nos sedimentos do Grupo Tubarão, a sedimentação detrítica concentrou preferencialmente illita e clorita a partir da erosão e deposição de fragmentos de rochas-fonte do Escudo Brasileiro. Sedimentos onde há uma grande concentração de argilominerais, como 


\section{Raphael Hypolito et al.}

constatado na amostra de argilito SED2Ae, constituem um reservatório potencial de flúor.

A liberação do $\mathrm{F}^{-}$da fase sólida para a água requer condições alcalinas do meio aquoso com elevados conteúdos de $\mathrm{OH}^{-}$e pH superior a 7,5, uma vez que essas condições favorecem a troca iônica de $\mathrm{OH}^{-}$por $\mathrm{F}^{-}$nos minerais (Hem, 1985; Ampabire et al., 1997; Banks et al., 1998; Saxena \& Ahmed 2001), condições estas observadas nas águas subterrâneas da região.

Outro fator que pode influir na liberação de $\mathrm{F}^{-}$é a condutividade específica (750 a 1750 $\mu \mathrm{S} / \mathrm{cm}$ ) (Saxena \& Ahmed, 2001), não tendo sido observado, entretanto, uma correlação positiva entre os parâmetros condutividade específica e concentração de flúor nas amostras analisadas.

As águas enriquecidas em $\mathrm{F}^{-}$nos poços tubulares da região são, predominantemente, bicarbonatadas e, secundariamente, bicarbonatadas-sulfatadas, caracterizando águas alcalinas. Essas anomalias também foram descritas por diversos autores em águas bicarbonatadas sódicas, sulfatadas ou cloretadas sódicas (Szikszay et al., 1981; Kimmelmann \& Silva, 1990; Fraga, 1992; Ampabire et al., 1997; Banks et al., 1998; Kim \& Jeong, 2005; Guo et al., 2007; Nanni, 2008, entre outros). Chae et al. (2007) observou que a concentração de fluoretos decresce na seqüência de grupo de classificação de águas: $\mathrm{Na}-\mathrm{HCO}_{3} \gg \mathrm{Na}-\left(\mathrm{SO}_{4}\right)-\mathrm{Cl} \gg \mathrm{Ca}-\left(\mathrm{SO}_{4}\right)-\mathrm{Cl} \geq \mathrm{Ca}-\mathrm{HCO}_{3}$.

As amostras de água analisadas apresentam consideráveis concentrações de $\mathrm{Na}^{+}$e relativamente baixas concentrações tanto de $\mathrm{Ca}^{2+}$ como de $\mathrm{Mg}^{2+}$. Isso pode ser conseqüência de processos de troca catiônica de $\mathrm{Ca}^{2+}\left(\mathrm{Mg}^{2+}\right.$ e $\left.\mathrm{H}^{+}\right)$por $\mathrm{Na}^{+}$nos minerais onde essa troca catiônica é influenciada pelo $\mathrm{pH}$ da água, podendo ocorrer tanto em argilominerais da superfície de falha dos granitos como nos sedimentos, conforme também constatado nos trabalhos de Gascoyne (2004), Boyle (1992) e Chae et al. (2007). Por outro lado, em águas com $\mathrm{HCO}_{3}^{-}$, a solubilização de $\mathrm{F}^{-}$é favorecida ao invés de precipitação como fluorita $\left(\mathrm{CaF}_{2}\right)$, apesar de sua baixa solubilidade, além da precipitação do $\mathrm{Ca}^{2+}$ como carbonato, conforme a reação $\mathrm{CaF}_{2}(\mathrm{~s})+2 \mathrm{HCO}_{3}^{-}(\mathrm{aq})=\mathrm{CaCO}_{3}(\mathrm{~s})+2 \mathrm{~F}^{-}(\mathrm{aq})+\mathrm{H}_{2} \mathrm{O}(\mathrm{l})+\mathrm{CO}_{2}$ (g) (Fraga, 1992; Saxena \& Ahmed, 2001; Guo et al., 2007). Isto explica o baixo conteúdo de $\mathrm{Ca}^{2+}$ nas amostras de águas analisadas.

Outro mecanismo que pode ter sido responsável pela presença de flúor nas águas subterrâneas de Salto e Indaiatuba pode estar relacionado à percolação de fluidos associados a um evento magmático.

Fraga (1992) levanta a posssibilidade de esses fluidos estarem relacionados à colocação dos corpos granitóides durante o Brasiliano. Entretanto, as mineralizações de fluorita presentes em Santa Catarina encontram-se encaixadas em sedimentos do Subgrupo Itararé e desenvolveram, nas suas encaixantes, zonas de alteração hidrotermal (Savi, 1980). Adicionalmente, Viero et al., (2009) constataram que as anomalías de flúor presentes no aqüífero fraturado (gnaisses e granitos pré-cambrianos) e sedimentar (sedimentos argiloarenosos conozóicos) da região de Porto Alegre, no Rio Grande do Sul, estão associadas à dissolução de fluorita secundária que preenche fraturas que cortam gnaisses e granitos.

Também, na bacia do Paraná, há a presença de sedimentos ricos em flúor, como os folhelhos negros das Formações Ponta Grossa e Irati (Kern et al., 2008), os siltitos da Formação Corumbataí (Garcez et al., 2003) e os pelitos síltico-argilosos da Formação Santa Maria, no Rio Grande do Sul (Mariomon, 2006), assim como há presença de anomalias de flúor no Aqüífero Guaraní e no Aqüífero Serra Geral (Szikszay et al., 1981, Kimmelmann e Silva, 1990, Licht, 2001, Nanni, 2008).

Ampabire et al. (1997) indicam outros fatores que podem exercer influência sobre o comportamento do flúor, relacionando temperatura, $\mathrm{pH}$, presença de íons e colóides complexantes na solução, solubilidade dos minerais que contêm flúor, características de formações geológicas percoladas pelas águas e tempo em que as águas estão em contacto com um determindado tipo de rocha.

$\mathrm{Na}$ área de estudo, deve-se levar em consideração que os granitóides do Complexo Itu são muito pobres em máficos e seria questionável se o tempo transcorrido entre a sua colocação no final do Neopaleozóico/Proterozóico Superior (Galembeck, 1997) e a deposição do Subgrupo Itararé, no Permocarbonífero, seria suficiente para que processos de hidrólise atuassem provocando enriquecimentos significativos de flúor nas águas subterrâneas da região.

Savi (1980) associa a gênese das mineralizações de fluorita de Santa Catarina ao processo de rifteamento e de separação do supercontinente Gondwana durante o Mesozóico. Tanto as mineralizações de fluorita, a presença de flúor em sedimentos, assim como as anomalias de flúor nos aqüíferos Cristalino, Tubarão, Guarani e Serra Geral, no contexto da bacia do Paraná, poderiam possuir uma origem comum atribuída à colocação de grandes volumes de lava relacionadas ao processo de separação de América do Sul e África, gerando o oceano Atlântico Sul. Um evento magmático dessas proporções estaria associado à circulação de volumes muito grandes de fluidos hidrotermais, os quais poderiam facilmente percolar falhas reativadas ou geradas devido ao regime extensivo atuante durante o processo de separação do supercontinente, permitindo a interação dos mesmos tanto com as rochas cristalinas do embasamento (rochas metamórficas e granitóides) como com as rochas sedimentares da bacia do Paraná depositadas previamente, percolando, também, os derrames de basaltos. Esses fluidos hidrotermais estariam enriquecidos em flúor extraído do manto que constitui um reservatório deste íon (Edgar \& Arima, 1985). Frank et al. (2007) postularam a hipótese de que a contaminação de flúor dos aqüíferos da bacia do Paraná esteja associada à degasificação de intrusivas da Formação Serra Geral. 
Esses mecanismos são corroborados pela presença de fluoretos associados à atividade vulcânica e gases fumarólicos (Hem, 1985) na região do Rift do Leste Africano, Quênia (Garici \& Davies, 1993) e à presença de águas termais, com $\mathrm{pH}$ elevado, ricas em fluoretos (Edmunds \& Smedley, 1996; Kundu et al., 2001).

Szikszay et al. (1981) reconhecem as direções NS e EW como alinhamentos principais no Estado de São Paulo. Segundo Zalan et al. (1991), a direção NW constitui a direção preferencial de colocação de diques de diabásio na bacia do Paraná. Licht (2001) menciona que em áreas com intersecções de lineamentos NW e NE, no Estado do Paraná, observam-se anomalias de fluoreto em águas subterrâneas, enquanto Nanni (2008) associa essas anomalias a estruturas tectônicas de direção NW na Formação Serra Geral. As fraturas mineralizadas em fluorita em Santa Catarina estão dispostas segundo as direções NW e NS (Savi, 1980; Zalán, 1991).

$\mathrm{Na}$ área estudada, observa-se um alinhamento preferencial dos poços tabulares que possuem águas enriquecidas em flúor na direção NW e um padrão de drenagem condicionado principalmente por lineamentos NW, mas também segundo lineamentos NE e NS (Figura 1). No campo, foram observadas falhas normais NW com rejeitos de até várias dezenas de metros cortando os granitóides e as rochas do Subgrupo Itararé e a nordeste da área estudada, na região de Campinas, os diques de diabásio estão orientados preferencialemnte na direção NS (Fernandes, 1997). Zalán et al. (1991) apontam a direção NE como pouco favorável à presença de diques de diabásio.

Assim, na área de estudo, a participação de fluidos hidrotermais mesozóicos implicaria a existência de um controle estrutural preferencial NW e NS, que favoreceriam o enriquecimento de flúor nos poços tabulares. Fluidos hidrotermais enriquecidos em flúor retirado do manto podem ter sido, posteriormente, ainda mais enriquecidos nesse íon atra- vés de processos de troca iônica com as rochas encaixantes, promovendo um subseqüente enriquecimento das águas subterrâneas em flúor, como constatado na região de Nayagarh, distrito de District Orissa, na Índia (Kundu et al., 2001).

As águas subterrâneas dos poçoscacimba apresentam características distintas, comparativamente aos demais aqüíferos, possuindo $\mathrm{pH}$ ácido, baixa condutividade elétrica e baixos teores de íons como $\mathrm{Ca}^{2+}, \mathrm{Na}^{2+}, \mathrm{Cl}^{-}, \mathrm{SO}_{4}{ }^{2-}$ e $\mathrm{HCO}_{3}{ }^{-}$, se comparadas com as águas dos poços tubulares (Tabela 1). A composição dessas águas pode ser conseqüência de uma influência muito grande de águas meteóricas, de recarga recente e da rápida interação com os minerais constituintes presentes no aqüífero freático. Os baixos teores de $\mathrm{F}^{-}$dessas águas (média $0,10 \mathrm{mg} \mathrm{dm}^{-3}$ ) indicam pouca ou nenhuma interferência de atividades antrópicas e as excluem como sendo uma fonte potencial de flúor que poderia abastecer reservatórios mais profundos. Reforçam, portanto, as hipóteses de que o flúor nas águas dos poços tubulares é originado da solubilização das rochas e/ou percolação de fluidos hidrotermais anteriormente discutidas.

\section{Conclusões}

A ocorrência de fluoreto em elevadas concentrações na região de Salto e Indaiatuba (SP) foi interpretada como uma anomalia natural dos Aqüíferos Tubarão, granular, e Cristalino, fissural. Suas águas são tipicamente bicarbonatadas e bicarbonatadas-sulfatadas, com altas concentrações de $\mathrm{HCO}_{3}^{-}$e $\mathrm{Na}^{+}$e elevados valores de $\mathrm{pH}(7,5-10,0)$. As maiores concentrações de $\mathrm{F}^{-}$ocorrem em poços dos aqüíferos Tubarão e poços mistos Tubarão/Cristalino.

A fonte do fluoreto nos Aqüíferos Tubarão e Cristalino pode ser atribuída à interação de águas alcalinas com biotita presente nos corpos granitóides e argilominerais presentes nas rochas sedimentares e/ou à percolação de fluidos hidrotermais ricos em flúor, associados ao evento de colocação de extensos volumes de lava, devido à quebra do Supercontinente Gondwana e abertura do Atlântico Sul, através de fraturas. Fluidos hidrotermais provenientes desse evento magmático Mesozóico estariam associados, na área de estudo, a um controle estrutural preferencial NW e NS. As maiores anomalias de flúor observadas nos Aqüíferos Tubarão e Cristalino poderiam também ser explicadas devido à sobreposição desses dois processos.

As águas do aqüífero freático captadas no manto de intemperismo não apresentam anomalias de flúor, possuem $\mathrm{pH}$ ácidos e baixas condutividade elétrica e teores de $\mathrm{Ca}^{2+}, \mathrm{Na}^{2+}, \mathrm{Cl}^{-}, \mathrm{SO}_{4}{ }^{2-} \mathrm{e}$ $\mathrm{HCO}_{3}^{-}$. Entretanto, essas águas apresentam maior vulnerabilidade a processos de contaminação antrópica.

\section{Agradecimentos}

Ao CEPAS (IGc/USP) pela infra-estrutura laboratorial. À FAPESP (Processo $\mathrm{N}^{\circ}$ 06/51699-0) e ao CNPq (Projeto $\mathrm{N}^{\mathrm{o}}$ 473081/2006-7). Ao Sr. Francisco Antonio Moschini, da Prefeitura Municipal de Salto-SP, pela sua ajuda nos trabalhos de campo. Aos relatores que muito contribuíram com os seus comentários.

\section{Referências bibliográficas}

ALMEIDA, F.F.M., HASUI,Y., PONÇANO, W.L., DANTAS,A.S.L., CARNEIRO, C.D., MELO, M.S., BISTRICHI, C.A. Mapa Geológico do Estado de São Paulo. São Paulo: IPT, v. 1, 1981. (Monografias 6).

ALLMANN, R., KORITNIG, S. Fluorine. In: WEDEPHL, K.H. (ed.). Handbook of Geochemistry. v. II/1. Berlin: SpringerVerlag, 1969, cap. 9, p.9-B - 9-O.

AMPABIRE, W.B., BOYLE, E.R., MICHEL, F.A. Geochemistry, genesis and health implications of fluoriferous graoundwaters in the upper regions of Ghana. Environmental Geology, v. 33, n.1, p.13-24, 1997.

APHA - American Public Health Associaton. Standard methods for examination of water and wastewater. $19^{\text {th }} \mathrm{ed}$. Washington: APHA, American water works Association, Water environment Federation, 1995. 
Raphael Hypolito et al.

B A K S , D., REIMANN, C., SKARPHAGEN, H. The comparative hydrochemistry of two granitic island aquifers: The Isles of Scilly, UK and the Hvaler Islands, Norway. The Science of the Total Environment, v. 209, p.169183, 1998.

BOYLE, D.R. Effects of base exchange softening on fluoride uptake in groundwaters of the Moncton SubBasin, New Brunswick, Canada. In: KHARAKA, MAEST (eds.) Water-Rock Interaction. Rotterdam: Balkema, 1992. p. 771-774.

CHAE, G.T., YUN,S.T., KWON, M.J., KIM, Y.S., MAYER, B. Batch dissolution of granite and biotite in water: Implication for fluorine geochemistry in groundwater. Geochemical Journal, v. 40, p. 95-102, 2006.

CHAE, G.T., YUN, S.T., MAYER, B., KIM, K.H., KIM,S.Y., KWON, J.K., KIM,K., $\mathrm{KOH}, \mathrm{Y}$. Fluorine geochemistry in bedrock groundwater of South Korea. Science of the Total Environment, v.385, p. 272-283, 2007.

CONCEIÇÃO, F.T., BONOTTO, D.M. Transferência de metais pesados, flúor e radionuclídeos para solos agrícolas na bacia do Rio Corumbataí. Geociências, v.24, n.1, p. 67-76, 2005.

EDGAR, A.D., ARIMA, M. Fluorine and chlorine contents of phlogopites crystallized from ultrapotassic rock compositions in high pressure experiments: implications for halogen reservoirs in source regions. American Mineralogist, 70, p. 529-536, 1985.

EDMUNDS, W.M., SMEDLEY, P.L. Groundwater geochemistry and health: an overview. In: APPLETON, FUGE, MCCALL (eds.) Environmental Geochemistry and Health. Geological Society Special Publication, v. 113, p.91-105, 1996

FERNANDES, A.J. Tectônica cenozóica na porção média da bacia do Rio Piracicaba e sua aplicação à hidrogeologia. São Paulo: Instituto de Geociências, Universidade de São Paulo, 1997. 244p. (Tese de Doutorado).

FRAGA, C.G. Origem de fluoreto em águas subterrâneas dos sitemas aqüíferos Botucatu e Serra Geral da bacia do Paraná. São Paulo: Instituto de Geociências, Universidade de São Paulo, 1992, 178p. (Tese de Doutorado).

FRANK, H.T., GOMES, M.E.B., FORMOSO, M.L.L., GARCIA, G.G. Contaminação de flúor dos aqüíferos da bacia do
Paraná derivada da desgaseificação de intrusivas da Formação Serra Geral: nova hipótese. In: ENCON. NAL. PERF. POÇOS, 15 e SIMP. HIDROGEOL. SUL-SUDESTE, 1. Anais... Natal: ABAS, 2007. 12p. (CD-ROM).

FLORÊNCIO, R. V. S. As argilas do Subgrupo Itararé: potencialidades como matérias-primas cerâmicas e como inertizadoras de resíduos industriais. São Paulo: Instituto de Geociências, Universidade de São Paulo, 2000. (Tese de Doutorado).

GALEMBECK, T.M.B. O Complexo Múltiplo, centrado e plurisserial Itu SP. Rio Claro: Instituto de Geociências e Ciências Exatas, Universidade Estadual Paulista, 1997. 374 p. (Tese de Doutorado).

GALEMBECK, T. M. B.; WERNICK, E.; GODOY, A. M. Tipologia de Granitos I eA(Rapakivi) coexistentes no Complexo Granitóide Itu, SP. São Paulo, UNESP. Geociências, v. 20, n.1, p. 25-36, 2001.

GARCEZ, L.L., SANT'AGOSTINO, L.M., MOTTA, J.F.M. A presença de flúor nos siltitos da Formação Corumbataí e o impacto ambiental causado por sua liberação durante o processo produtivo de revestimentos cerâmicos na região de Santa Gertrudes - SP. São Paulo: Instituto de Geociências, Universidade de São Paulo, 2003. 54p. (Monografia).

GARICI, S.J., DAVIES, T.C. The occurrence and geochemistry of fluoride I some natural waters of Kenya. Journal of Hydrology, v. 143, p. 395-412, 1993.

GASCOYNE, M. Hydrogeochemistry, groundwater ages and sources of salts in a granitic batholith on the Canadian Shield, souteastern Manitoba. Applied Geochemistry, v. 19, p. 519-560, 2004.

GUO, L., WANG, Y., MA, T.. MA, R. Geochemical processes controlling the elevated fluoride concentrations in groundwaters of the Taiyuan Basin, Northern China. Journal of Geochemical Exploration, v. 93, p. 1-12, 2007.

HEM, J.D.H. Graphical methods for studies of aqueous aluminium hydroxide, fluoride and sulfate complexes. U.S. Geological Survey Water Supply - Paper 1827-B, 1968. 33p.

HEM, J.D.H. Study and Interpretation of the Chemical Characteristics of Natural Water. 3rd Ed. U.S. Geological Survey Water-Supply - Paper 2254. USGS Department of the Interior, United States Government Printing Office, 1985.

HYPOLITO, R., ANDRADE, S., SILVA, L.H., NASCIMENTO, S.C. Alcalinidade - Metodologia para Determinação em Campo. Analytica, v. 35, p. 52-61, 2008.
IPT - INSTITUTO DE PESQUISAS TECNOLÓGICAS DO ESTADO DE SÃO PAULO. Estudo dos teores anômalos de fluoretos em águas dos aqüíferos Botucatu e Serra Geral no Estado de São Paulo. Primeira etapa de trabalho: Análise dos dados disponíveis. Relatório do IPT n ${ }^{\circ}$ 24123, v. 1 e2. 1986.

KERN, M.L., VIEIRO, A.P., MACHADO, $G$. The fluoride in the groundwater of Guarani Aquifer System: the origin associated with black shales of Paraná Basin. Environmental Geology, v. 55, n.6, p. 1219-1233, 2008.

KIM, K., JEONG, Gi Y. Factors influencing natural occurrence of fluoride-rich groundwaters: a case study in the sourheasterns part of the Korean Peninsula. Chemosphere, 58, p. 13991408, 2005.

KIMMELMANN E SILVA, A. A. Considerações sobre anomalias de fluoreto no Sistema Aqüífero BotucatuPirambóia, na bacia do Paraná. In: CONGRESSO BRASILEIRO DE ÁGUAS SUBTERRÂNEAS, 6. Anais... Porto Alegre: ABAS, 1990, p. 107-111.

KUNDU, N., PANIGRAHI, M.K., TRIPATHY, S., MUNSHI, S., POWELL, M.A., HART, B.R. Geochemical appraisal of fluoride contamination of groundwater in the Nayagarh District of Orissa, India. Environmental Geology, v.41, p. 451-460, 2001

LICHT, A.O.B. A geoquímica multielementar na gestão ambiental - identificação e caracterização de províncias geoquímicas naturais, alterações antrópicas da paisagem, áreas favoráveis à prospecção mineral e regiões de risco para a saúde no Estado do Paraná, Brasil. Curitiba: Universidade Federal do Paraná, 2001. 236 p. (Tese de Doutorado).

MARIMON, M.P.C. O flúor nas águas subterrâneas da formação Santa Maria, na região de Santa Cruz do Sul e Venâncio Aires, RS, Brasil. Porto Alegre: Instituto de Geociências da Universidade Federal do Rio Grande do Sul, 2006. 165p. (Tese de Doutorado).

NANNI, A.S. O flúor em águas o Sistema Aqüífero Serra Geral no Rio Grande do Sul: origem e condicionamento geológico. Porto Alegre: Instituto de Geociências da Universidade Federal do Rio Grande do Sul, 2008. 127p. (Tese de Doutorado).

NEVES, M. A. Análise integrada aplicada à exploração de água subterrânea na bacia do Rio Jundiaí (SP). Rio Claro: Instituto de Geociências e Ciências Exatas - IGCE/UNESP, 2005. (Tese de Doutorado). 
OZSVATH, D.L. Fluoride concentrations in crystalline bedrock aquifer Marathon County, Wisconsin. Environmental Geology, v.50, p.132-138, 2006.

PANAGOULIAS, T. I., SILVA FILHO, E. V. Estudo hidrogeoquímico do flúor nas águas subterrâneas das bacias dos Rios Casseribú, Macacu e São João, Estado do Rio de Janeiro. In: SILVA, C.R., FIGUEIREDO, B.R., CAPITANI, E.M., CUNHA, F. G. (Org.). Geologia Médica no Brasil. Efeitos dos materiais e fatores geológicos na saúde humana e meio ambiente. Rio de Janeiro: CPRM, 2006, v. 1, p. 126-129.

PASCHOLATI, E.M. Caracterização geofísica da suíte intrusiva de Itu. São Paulo: Instituto de Geociências de Universidade de São Paulo - USP, 1990. (Tese de Doutorado).

PETRI, S., PIRES, F.A. O Subgrupo Itararé (Permocarbonífero) na região do Médio Tietê, Estado de São Paulo. Revista Brasileira de Geociências, v. 22, n. 3, p. 301-310, 1992.

PINHEIRO, C.E., CARVALHO, A.C., VONO, B.G., ZARAMELLA, A. Estudo preliminar sobre o tero de flúor das águas da Região de Pereiras (Estado de São Paulo, Brasil). Rev. Inst. Méd. Trop. São Paulo, 1, p. 228-232, 1965.

RAMOS, A. N., FORMOSO, M.L.L. Argilominerais das rochas sedimentares da bacia do Paraná. Rio de Janeiro: PETROBRAS/ CENPES/DINTEP, 1975. (Série Ciência-Terra-Petróleo. Seção: Exploração de petróleo. Publ. n.9).

RIBEIRO, R.G. Contribuição ao estudo do fluoreto nas águas subterrâneas da bacia do Médio-Tietê (região de Piracicaba) caracterização e metodologias propostas para sua extração. São Paulo, Instituto de Geociências da Universidade de São Paulo, 1992. (Dissertação de Mestrado).

ROCHA-CAMPOS, A.C. The Tubarão Group in the Brazilian portion of the Paraná Brasil. In: BIGARELLA, J.J., BECKER, R.D., PINTO, I.D. (eds) Problems in Brazilian Gondwana Geology. Curitiba: IUGS, p. 27-102, 1967.

SAAD, A.R. Estratigrafia do Subgrupo Itararé no centro e sul do Estado de São Paulo. São Paulo: Instituto de Geociências da Universidade de São Paulo, 1977. (Tese de Doutorado)

SALVETTI, R.A.P. Sistemas deposicionais e paleogeográficos do subgrupo Itararé (Neopaleozóico da bacia do Paraná), na região de Itu e Indaiatuba, SP. São Paulo: Instituto de Geociências da Universidade de São Paulo, 2005. (Dissertação de Mestrado).

SANTOS, P.R. dos, ROCHA-CAMPOS, A.C., CANUTO, J.R. Patterns of late Palaeozoic deglaciation in the Paraná Basin, Brazil. Palaeoge. Palaeocli. Palaeoeco., v.125, p.165-184, 1996.

SAXENA, V.K., ASHMED, S. Dissolution of fluoride in groundwater: a water-rock interaction study. Environmental Geology, v. 40, p.1084-1087, 2001.
SAVI, C. N. Gênese e controle das mineralizações de fluorita da região de Criciúma-SC. Brasília, Instituto de Geociências da Universidade de Brasília. 1980. (Tese de Doutorado).

SILVÉRIO DA SILVA, J.L., FLORES, E.M., BERTAZZO, V.M. Estudo hidroquímico das águas subterrâneas da Região de Santa Maria, Estado do Rio Grande do Sul. In: CONGR. BRAS. ENG. SANIT. AMB., 23, 2006. Fortaleza. Anais... Fortaleza: ABES, CD-ROM, 2006. 10p.

SOUZA, P.A. Late Carboniferous palynostratigraphy of the Itarare Subgroup, northeastern Paraná Basin, Brazil. Rev. Palaeob. Palynol., v. 138, p.9-29, 2006.

SRACEK, O., HIRATA, R. Geochemical and stable isotopic evolution of the Guarani Aquifer System in the State of São Paulo, Brazil. Hydrogeology Journal, v. 10, p.643-655, 2002.

STEVAUX, J.C., SOUZA FILHO, E.E. DE, TEIXEIRA, J.A., LANDIM, P.M.B. Sistemas deposicionais do Subgrupo Itararé (PC) na bacia Hidrográfica do Baixo Rio Capivari (SP): um modelo para prospecção de água subterrânea. In: SIMP. REG. GEOL., 6, 1987. Atas... Rio Claro: SBG-NSP, 1987, v. 1, p. 355-374.

SZIKSZAY, M., TEISSEDRE, J.M., BARNER, U., MATSUI, E. Geochemical and isotopic characteristics of spring and groundwater in the State of São Paulo, Brazil. Journal of Hydrology, Amsterdam, v.54, p. 23-32, 1981.

VELÁSQUEZ, L.N., COSTA, W.D., FANTINEL, L.M., UHLEIN, A., FERREIRA, E.F., CASTILHO, L.S. Controle estrutural do fluoreto no Aqüífero Cárstico do Município de São Francisco, MG. In: CONGR. BRAS. ÁGUAS SUBTERR., 13, Anais... Cuiabá: ABAS, 2006, CD-ROM, 26p.

VIERO, A.P., ROISENBERG, C., ROISENBERG, A., VIGO, A. The origin of fluoride in the granitic aquifer of Porto Alegre, Souterhn Brazil. Environmental Geology, v. 56, p. 1707-1719, 2009.

WHO - World Heath Organization. Fluoride in Drinking-water. World Health Organization titles with IWA Publishing. Printed by TJ International (Ltd), Padstow, Cornwall, UK. 2006, 144p.

ZALÁN, P.V., WOLF, S., CONCEIÇÃO, J.C. DE J., MARQUES, A., ASTOLFI, M.A. M., VIEIRA, I.S., APPI, V.T., ZANOTTO, O.A. Bacia do Paraná. In: PETROBRÁS. RAJA GABAGLIA, G.P., MILANI, E.J. (eds.). Origem e evolução de bacias sedimentares. Rio de Janeiro: 1990. p. 135-168.

ZALÁN, P.V., WOLF, S., CONCEIÇÃO, J.C.J., ASTOLFI, M.A.M., VIEIRA, I.S., APPI, V.T., ZANOTTO, O.A., MARQUES, A. Tectonics and sedimentation of the Paraná Basin. In: ULBRICH, H., ROCHA CAMPOS, A. C. (eds.) Gondwana Seven. Proceedings. São Paulo, 1991. p. 83-117.

ZHU, C., SVERJENSKY, D. A. Partitioning of F-Cl-OH between minerals and hydrothermal fluids. Geochimica et Cosmochimica Acta, v.55, p 1837-1858, 1991.

Artigo recebido em 06/07/2009 e aprovado em 09/07/2010.

\section{A REM tem novo endereço: FUNDAÇÃO GORCEIX - REM Rua Carlos Walter Marinho Campos, 57 Bairro: Vila Itacolomy 35400-000 - Ouro Preto - MG}

